\title{
Design, fabrication, and characterization of a proposed microchannel water electrolyzer
}

\author{
Muhammed E. Oruc, ${ }^{a}$ Amit V. Desai, ${ }^{a}$ Ralph G. Nuzzo ${ }^{b}$ and Paul J. A. Kenis, ${ }^{a, *}$ \\ ${ }^{\mathrm{a}}$ Department of Chemical \& Biomolecular Engineering, ${ }^{\mathrm{b}}$ Department of Chemistry \\ University of Illinois at Urbana-Champaign, Urbana, IL 61801, USA
}

\begin{abstract}
Solar energy-powered water electrolysis is a cost-effective and scalable method to produce hydrogen, an environment-friendly and potentially sustainable energy carrier. To this end, we report a microchannel water electrolyzer with a planar design that can be integrated with a photovoltaic cell, where the electrolyzer utilizes the waste heat generated during the photoelectric process to enhance the production of hydrogen (and oxygen) via the electrochemical splitting of water. We performed a systematic parametric investigation to study the effect of the channel dimensions, electrolyte temperature and flow rate, and the mode of operation (pulsed $v s$. continuous) on the electrolyzer's performance. The balance between mass, heat and ion/charge transport limitations acts to determine an optimal geometry and specific operating conditions for the device. The highest hydrogen production rate was observed for pulsed operation ( $15 \mathrm{~s}$ pulses) at a temperature of $60^{\circ} \mathrm{C}$, and a potential of $2.0 \mathrm{~V}$, for a $400-\mu \mathrm{m}$ tall electrolyzer chamber. We also show that tuning of the geometry and operating conditions can yield an almost 7-fold increase in the hydrogen production rate. This study not only reports a new and improved approach over existing photovoltaic thermal systems but also presents design and operational considerations for microfluidic-based electrochemical energy devices.
\end{abstract}

Keywords: Photovoltaic thermal systems; PDMS electrolyzer; pulsed operation for electrolyte transport; mass/heat/ion/charge transport limitation; platinum black on gold electrodes.

*Corresponding author: (217) 244-9214, kenis@illinois.edu 


\section{Introduction}

Hydrogen is an environment-friendly and a sustainable energy carrier. A sustainable method to produce hydrogen is the electrolysis of water powered by renewable energy sources. Amongst these various methods based on renewable sources, solar energy-driven electrolysis, i.e., photoelectrolysis, is the least expensive and most effective way to produce hydrogen [1-3], where the electricity produced by the photoelectric conversion process (solar energy to electrical energy) is used to power the electrolysis process. Several studies have explored the direct (integrative) coupling of a photovoltaic (PV) cell with a water electrolyzer [4-7]. A few of these prior reports have also focused on different approaches that can be used to maximize the hydrogen production, e.g., matching of the voltage and maximum power output of the PV cell to the operating voltage of the electrolyzer $[4,5,8]$. Another simple approach to increase the hydrogen production would be to increase the operating temperature of the electrolysis cell, as higher temperatures lead to higher $\mathrm{H}_{2}$ production due to faster reaction kinetics. This approach follows guidance from commercial water electrolyzers (alkaline electrolyzers), which typically operate at higher temperatures $\left(60\right.$ to $\left.90^{\circ} \mathrm{C}\right)[9,10]$.

Different methods have been used to increase the electrolysis temperature, such as preheating the electrolyte or direct heating of the electrolyzers [9]. Although these methods have been effective in increasing the $\mathrm{H}_{2}$ production, these methods decrease the overall efficiency of a hybrid PV-electrolyzer system due to the additional energy input required for heating to increase the electrolyte temperature [11]. Licht et al. proposed a new way, photothermal electrochemical process, in order to increase the efficiency of solar water splitting systems $[12,13]$. In the process of the STEP (solar thermal electrochemical photo) production of hydrogen, concentrated radiation is split into visible and infrared regions. Visible region assists electricity generation in 
the solar cell (objected to power electrolyzers) and the latter one provides heat supply for the hydrogen production in the molten salt electrolyzers. The higher heat assistance reduces the operating voltage up to $1.4 \mathrm{~V}$ at $700{ }^{\circ} \mathrm{C}$ in these electrolyzers, which reduces the cost of hydrogen production[14]. On the other hand, this system requires higher capital investments and cautious operating conditions. To address this issue, we describe a different and a simple architecture as the traditional photovoltaic thermal (PVT) systems that utilize the waste heat generated by the photoelectric process for room or water heating (as opposed to hydrogen production). We term this hybrid or integrated system as 'photovoltaic thermal water electrolyzer' or PVTE that utilizes the waste heat generated by the photoelectric process to increase the electrolysis temperature, and thus increase the hydrogen production without using any external heat source. The proposed system doesn't require complicated configuration relative to STEP systems, and lower operating temperatures $\left(\sim 60^{\circ} \mathrm{C}\right)$ provides to use this system with any installed PV cells.

The proposed PVTE comprises a planar microchannel water electrolyzer positioned underneath a PV cell (Fig 1(a)), which enables the waste heat to directly increase the electrolyte temperature and consequently reduce the overpotentials and provide faster electrode kinetics. Part of the electricity generated by the photoelectric conversion is used for the electrolysis process, while the remaining electricity is supplied to the grid. Additionally, the microchannel electrolyzer removes the waste heat and functions as a heat sink, which reduces the temperature of the PV cell and thus increases the efficiency of the photoelectric conversion process $[15,16]$. An empowering attribute afforded by this design is that, once heated, the electrolyte can be circulated and stored in an insulated tank for room or water heating [17-19]. Hence in addition to the standard outputs of current commercial PVT systems, i.e., electricity and thermal storage, the proposed PVTE system produces hydrogen as an energy output. In an earlier report, we 
described a comprehensive energy analysis on the PVTE system using finite-element analysis (FEA) simulations [20]. Here we focus specifically on the design, fabrication, operation and characterization of the microchannel water electrolyzer. For the engineering aspects of integration we follow the approaches presented by others in prior PVT hybrid systems (e.g. [4]). Although we describe the microchannel electrolyzer within the context of the PVTE system, the outcomes of this study, specifically the planar design and 'pulsed' operation, are applicable to microfluidic-based electrochemical energy devices in general. For example, we simulated the envisioned integrated PVTE system in other work [20].

\section{Experimental}

\subsection{Electrode preparation}

The procedure for preparing the electrodes is illustrated in Fig. 2 (left half). The electrode pattern was created on a glass slide $\left(40 \mathrm{~mm} \times 40 \mathrm{~mm} \times 1 \mathrm{~mm}\right.$, Ted Pella, Corning ${ }^{\circledR}$ Glass Slides, \#26005) using photolithography ( 2 $\mu \mathrm{m}$ positive photoresist AZ-5214 was used). Then electron-beam deposition was used to deposit a $\sim 10 \mathrm{~nm}$ thick film of titanium (Ti) adhesion layer, followed by a $\sim 150 \mathrm{~nm}$ gold ( $\mathrm{Au}$ ) layer under a vacuum of $\sim 2 \times 10^{-7}$ mbar. Then the golddeposited electrodes $\left(\sim 2 \mathrm{~cm}^{2}\right.$ area per electrode) were electrochemically cleaned by cycling between 0.2 and $1.45 \mathrm{~V}(\mathrm{Ag} / \mathrm{AgCl}$ reference electrode, Bioanalytical Systems, Inc., $7.5 \mathrm{~cm}$ long RE-5B reference electrode) at $25 \mathrm{mV} \mathrm{s}^{-1}$ in $0.5 \mathrm{M} \mathrm{H}_{2} \mathrm{SO}_{4}$ (Sigma-Aldrich) solution. After cleaning, the electrodes were electrochemically platinized at $0.5 \mathrm{~V}(\mathrm{Ag} / \mathrm{AgCl})$ for $30 \mathrm{~s}$ in a $3 \mathrm{wt}$. $\% \mathrm{H}_{2} \mathrm{PtCl}_{6} \cdot 6 \mathrm{H}_{2} \mathrm{O}$ (Sigma-Aldrich) $+0.03 \%$ lead-acetate (Sigma-Aldrich) solution in water to yield porous platinum $(\mathrm{Pt})$ electrodes. After the deposition step, the electrodes were thoroughly rinsed with milli-Q water and electrochemically cleaned by cycling from -0.2 to $1.1 \mathrm{~V}$ $(\mathrm{Ag} / \mathrm{AgCl})$ at $25 \mathrm{mV} \mathrm{s}^{-1}$ in $0.5 \mathrm{M} \mathrm{H}_{2} \mathrm{SO}_{4}$ solution. The experiments were performed in a 
conventional three-compartment electrochemical cell (Model 660D, CH Instrument), using a Ptwire counter electrode (Alfa Aesar, $0.5 \mathrm{~mm}$ diameter) and an $\mathrm{Ag} / \mathrm{AgCl}$ reference electrode.

\subsection{Fabrication of the water electrolyzer}

The fabrication flow for the water electrolyzer is shown in Fig. 2. A master for the microchannels was created by rapid prototyping using 3D printing (Viber Si Stereolithography, Protogen O-XT 18420 as the resin). The poly(dimethylsiloxane) or PDMS base and curing agent (Dow Corning) were mixed in a ratio of 10:1, poured onto the 3D printed master, and then cured at $70^{\circ} \mathrm{C}$ for 2 hours. The PDMS replica was peeled from the master and an inlet and two outlet holes were created using a biopsy punch. The PDMS mold and the patterned electrodes on glass were exposed to an activating plasma $\left(\mathrm{O}_{2}\right.$ gas, $\left.50 \mathrm{~W}\right)$ for $\sim 30$ seconds and the two surfaces brought into conformal contact to create the microchannel water electrolyzer [21]. An image of the fabricated water electrolyzer is shown in Fig. 1(b).

\subsection{Electrochemical testing}

To calculate the polarization overpotentials, the glass substrate with electrodes was immersed in $0.5 \mathrm{M} \mathrm{H}_{2} \mathrm{SO}_{4}$ electrolyte inside a conventional three-compartment electrochemical cell with an $\mathrm{Ag} / \mathrm{AgCl}$ reference electrode. The image of the experimental set up for electrolyzer is shown in Fig. S1 in the supplementary information. All the experiments were performed after pre-treating the electrodes with $1 \mathrm{M} \mathrm{H}_{2} \mathrm{SO}_{4}$ at $60{ }^{\circ} \mathrm{C}$ and under an applied voltage of $1.8 \mathrm{~V}$ for 2 hours. The amount of the hydrogen production was calculated based conversion of the measured current generated during electrolysis. A $30 \mathrm{~mm} \times 30 \mathrm{~mm}$ polyimide film insulated flexible heater (Omega Engineering) was attached to the glass substrate and a constant temperature was applied to the water electrolyzer using a temperature controller. Here in this measurement, the heat produced by the flexible heater is matched to mimic the waste heat generated by a Si PV 
cell in direct laminate contact under an AM 1.5 G irradiance, based on our prior work [17]. In our previous work, the simulation was performed with an integrated PV cell and a microchannel electrolyzer with a glass substrate. Therefore, instead of integrating the electrolyzer with a PV cell, we provided the same electrolyte temperature within the electrolyzer to observe the potential behavior of gas generation in the channels. The temperature of the electrolyte was measured immediately after leaving the microchannel electrolyzer and a decrease of $\sim 3^{\circ} \mathrm{C}$ relative to the set temperature was observed, probably due to heat losses during measurements. A syringe pump (Harvard PHD-2000) was used to supply $1 \mathrm{M} \mathrm{H}_{2} \mathrm{SO}_{4}$ at room temperature to the electrolyzer chamber. During the experiments, a total potential of 1.8 or $2.0 \mathrm{~V}$ was applied continuously to the electrodes, and the electrolyte and evolved gases were flushed from the chamber through the two outlets by the syringe pump.

\section{Results and Discussion}

\subsection{Design of the microchannel water electrolyzer}

Microfluidic-based electrochemical energy devices have been widely researched because of their advantages of rapid heat and mass transfer leading to fast temperature changes, high surface area to volume ratio leading to fast reaction kinetics, and the small system size leading to the ability to manufacture portable devices [22-26]. Although microfluidics has been extensively explored for electrochemical energy devices such as fuel cells [27], very few reports in literature have focused on the application of microfluidics to generate hydrogen by electrolysis [28-30]. Here we demonstrate the potential of a microchannel-based design for a water electrolyzer to efficiently produce hydrogen. 
We chose to adopt a planar design for the electrolyzer as this design allows us to conveniently adjust the overall thickness and hence better tune the heat transfer. The ability for thermal management is not only important for efficient temperature control of the electrolysis process, but also to effectively remove heat from the PV cell within the integrated PVTE system. The planar design also reduces the space requirement for the electrolyzer and hence allows for convenient integration with the planar PV cell.

The electrolyzer was $40 \mathrm{~mm} \times 40 \mathrm{~mm} \times \sim 9 \mathrm{~mm}$, the electrolyzer chamber was $20 \mathrm{~mm} \times$ $20 \mathrm{~mm} \times 0.2$ or $0.4 \mathrm{~mm}$, and the approximate volume of the electrolyte in the chamber was 0.04 or $0.08 \mathrm{~mL}$ (Fig 1(b)). These values for the planar dimensions of the electrolyzer (20 and 40 $\mathrm{mm}$ ) were chosen to be compatible with the standard microfabrication procedures using a 4 inch diameter silicon wafer.

The thickness of the electrolyzer chamber is an important parameter governing the hydrogen production rate. In our previous energy analysis on the PVTE system [20], we showed that the optimum flow rate and chamber thickness was $0.65 \mathrm{~mL} \mathrm{~min}^{-1}$ and $0.4 \mathrm{~mm}$, respectively. For the same linear velocity, the use of taller channels (we tested from $0.2-1 \mathrm{~mm}$ previously [20]) will lead to lower hydrogen production as the electrolyte does not get sufficiently heated, especially for faster flow rates (lower residence time). Taller channels, however, lead to more efficient removal of evolved gases at the electrodes and thus higher electrolysis efficiency as taller channels enable the use of high flow rates (lower pressure drops compared to those in shallower channels) to flush out the evolved gases. Hence the typical thickness in PEM electrolyzers is $\sim 1 \mathrm{~mm}$ to allow for higher gas removal and bubble management in the stacks $[31,32]$. On the other hand, shallower channels not only ensure more efficient heating of the electrolyte (and consequently more hydrogen production) but also lead to lower ohmic losses (IR 
drop) due to a lower electrical resistance. In fact, in a previous study on the electrochemical characteristics of potassium ferrocyanide in sodium sulfate buffer using planar electrodes, the ohmic losses were reported to significantly increase when the channel thickness increased from $30 \mu \mathrm{m}$ to $200 \mu \mathrm{m}$ and slightly change between $200 \mu \mathrm{m}$ and $500 \mu \mathrm{m}$ [33]. As our main objective was to maximize hydrogen production, we chose to perform studies with taller channels (200, $400 \mu \mathrm{m})$ since the ohmic losses within the electrolyte is almost constant for these channel heights and the effect of these losses is not expected to significantly influence the hydrogen production.

For a $1000 \mathrm{~W} \mathrm{~m}^{-2}$ heat input, similar to the heat generated during by the photoelectric process, the $1 \mathrm{~mm}$ thick non-electrically conductive glass substrate results in a temperature difference of around $1^{\circ} \mathrm{C}$ across the glass [20], which ensures rapid heating of the electrolyte. Indeed, one can calculate that the Biot number is on the order of 0.01 for this system under these conditions, indicating that the temperature, while not $100 \%$ uniform, does not vary a lot within the electrolyte $(\mathrm{Bi}<0.1)$. The PDMS layer thickness $(7 \mathrm{~mm})$ was chosen to prevent heat loss from the flowing electrolyte as the electrolyte is supposed to remove and store the waste heat in the PVTE configuration. The PDMS reservoir included an inlet for the electrolyte at ambient temperature and two outlets for the two products of the electrolysis process, $\mathrm{H}_{2}$ and $\mathrm{O}_{2}$, with the heated electrolyte.

\subsection{Electrode characterization}

The cyclic voltammetry plots of the $\mathrm{Au}$ thin film and the Pt-black catalyst electrodeposited on a Au thin film (Fig $\mathbf{S 2}$ in supplementary information) is consistent with the characteristic behavior of Au and Pt. The porous Pt-black electrode leads to higher electrode kinetics per unit electrode area relative to a thin film Pt electrode [34]. Fig. 3(a) depicts the polarization curves of the Pt-black electrode in $0.5 \mathrm{M} \mathrm{H}_{2} \mathrm{SO}_{4}$ electrolyte for different electrolyte 
temperatures. The efficiency of the electrolysis process is $60 \%$ when the electrolyte is at room temperature and the current density is $10 \mathrm{~mA} \mathrm{~cm}$. When the temperature is elevated to $60^{\circ} \mathrm{C}$, the efficiency goes up to approximately $70 \%$ for the same current density.

The surface area or roughness of the platinum electrodes is known to decrease with electrolysis time [35]. Hence to ensure almost constant surface area during the experiment different pre-treatment approaches, such as thermal annealing [36] or electrolysis at approximately operating conditions [37], have been reported. Prior to our experiment, we pretreated the Pt-electrodes by electrolysis in $1 \mathrm{M} \mathrm{H}_{2} \mathrm{SO}_{4}$ at $60^{\circ} \mathrm{C}$ and $1.8 \mathrm{~V}$. We observed that a minimum of 2 hours of electrolysis time is required to minimize the effect of aging-mediated activity losses (Fig. 3(b)). Scanning electron microscope (SEM) micrographs (insets in Fig 3(b)) of the electrode at the beginning of the electrolysis and two hours later confirm the morphological changes, which supports the catalytic degradation over the initial two hours. Much smaller activity losses after these morphological changes are attributed to catalyst deactivation.

\subsection{Effect of chamber thickness on hydrogen production rate}

Our previous analysis [20] has shown that under a solar radiation of $1000 \mathrm{~W} \mathrm{~m}^{-2}$ and at ambient temperatures of $35{ }^{\circ} \mathrm{C}$ (typical conditions during summer afternoons in Phoenix, AZ) the electrolyte temperatures can reach as high as $60{ }^{\circ} \mathrm{C}$ and at these conditions the hydrogen production rate is up to 2.5 times higher than the case of the electrolyzer operating at ambient temperature. Hence for our experiments we varied the electrolyte temperature from 25 to $60{ }^{\circ} \mathrm{C}$.

As the channel thickness influences the mass transport resistance due to the bubble formation and gas evolution, we investigated the effect of channel thickness on hydrogen production rate. Fig 4(a) depicts the hydrogen production current for two different channel 
thicknesses $(200$ and $400 \mu \mathrm{m})$ and two different electrolyte temperatures $\left(25\right.$ and $\left.60{ }^{\circ} \mathrm{C}\right)$ for an electrolyte flow rate of $0.65 \mathrm{~mL} \mathrm{~min}^{-1}$ (determined to be the optimal value based on our prior FEM analyses [20]). Higher chamber thickness resulted in higher current density, which is probably due to lesser bubble formation and more efficient removal of evolved gases in taller channels leading to lower mass transport limitations. Although the IR drop across the lower chamber thickness will be lower and supposedly lead to higher current density [33], our observation of higher current density for the taller chamber suggests that the electrolysis in microchannels is more influenced by mass transport limitations than by limitations in conductivity (ion/charge transport). We observed higher current flux for higher temperatures due to the faster reaction kinetics. We additionally observed that, for the $200 \mu \mathrm{m}$ chamber thickness, the hydrogen production rate was almost constant after 5 seconds, suggesting that the mass transport limitation had been reached. In case of the $400 \mu \mathrm{m}$ chamber thickness, however, the current density continued decreasing even after 60 seconds, indicating that the faster reaction kinetics is a more important factor than the mass transport limitations influencing the hydrogen production. The results in this section highlight the influence of chamber thickness on hydrogen evolution. As we observed a better performance for a $400 \mu \mathrm{m}$ electrolyzer chamber, we used the taller electrolyzer for the remaining experiments.

\subsection{Effect of flow rate on hydrogen production rate}

As the electrolysis process is affected by mass transport limitations, the flow rate of the electrolyte is expected to influence the electrolyzer performance. The hydrogen production rate in terms of current flux at two different temperature, 25 and $50^{\circ} \mathrm{C}$, and for different flow rates is shown in Fig 4(b). The range of the flow rate was chosen to be such that the optimal rate (0.65

$\mathrm{mL} \min ^{-1}$ ) determined in our prior research [20] is at the lower end of the range, since higher 
flow rates are preferable to minimize mass transport limitations. At lower flow rates $(0.50$ and $0.65 \mathrm{~mL} \mathrm{~min}^{-1}$ ) the hydrogen production rate is lower due to accumulation of the produced gases $\left(\mathrm{H}_{2}\right.$ and $\left.\mathrm{O}_{2}\right)$ at the electrodes that leads to lower interaction between the electrode and electrolyte. At higher flow rates $\left(1\right.$ and $\left.5 \mathrm{~mL} \mathrm{~min}^{-1}\right)$ the current flux increases, which is due to the gases being more efficiently flushed out (and away from the electrodes) by the higher flow rates thus minimizing mass transport limitations. A similar positive correlation between current flux and flow rate was observed in the case of microfluidic vanadium redox fuel cell, which was attributed to the fact that the mass transport limitations are significant for lower flow rates in the case of fast electrochemical reactions [38]. Note that the reason for arriving at a lower value for the optimal flow rate $\left(0.65 \mathrm{~mL} \mathrm{~min}^{-1}\right)$ in our prior research [20] was that the optimum operating conditions were determined to maximize overall efficiency of the PVTE system, which included the efficiency of the coupled photoelectric conversion elements. In the PVTE system, lower flow rates led to higher temperatures of the PV cell and consequently a lower photoelectric conversion efficiency.

Interestingly at the higher temperature $\left(50{ }^{\circ} \mathrm{C}\right.$ ) the increase in flow rate (from 1 to $5 \mathrm{~mL}$ $\min ^{-1}$ ) did not improve the hydrogen production rate. Although higher flow rates minimize mass transport limitations, the higher rates reduce the residence time of the electrolyte within the chamber, which in turn leads to lower temperature of the electrolyte (heat transport limitations). To address this issue of balancing mass and heat transport limitations, we operated the electrolyzer using a pulsed or 'residence time' approach [39], where the electrolyte is pumped into the chamber, allowed to 'reside' in the chamber so that the electrolyte is sufficiently heated (thus minimizing heat transport limitations), and then chamber is flushed at a high flow rate to remove the produced gases (thus minimizing mass transport limitations). 
The current flux in the pulsed operation mode is shown in Fig. 5, where the residence time is maintained at $60 \mathrm{~s}$ and the flushing rate and volume is $10 \mathrm{~mL} \mathrm{~min}{ }^{-1}$ (higher than the fastest rate tested in previous experiments, Fig. 4(b)) and $0.16 \mathrm{~mL}$ (approximately twice the volume of the electrolyte within the chamber), respectively. The regular spikes for the $25^{\circ} \mathrm{C}$ plot imply that after flushing (or replacing the electrolyte) the hydrogen production rate rapidly regenerates and then again decreases close to the rate prior to flushing. When the operating temperature is $50^{\circ} \mathrm{C}$, however, two different behaviors are observed for the hydrogen production rate after replacing the electrolyte. In zone I, the flushing step removes the gases from the electrodes leading to an abrupt increase in hydrogen production with the increasing the temperature of incoming volume of the electrolyte (thermal response). In zone II, the produced gases begin to accumulate at the electrode and the hydrogen production begins to decrease due to mass transport limitations $[38,40]$. This effect is more pronounced at higher operating temperatures due to the faster reaction kinetics that obtain under those conditions. Thus we find that the total integrated current obtained over extended time (area under the curve) will be higher in case of the pulsed as compared to continuous flow mode of operation.

\subsection{Effect of applied voltage and temperature under pulsed operation}

To further optimize the electrolyzer performance, we considered the effect of temperature and applied voltage on the current flux under pulsed operation. Specifically we studied the hydrogen production rate as a function of different parameters for a residence time of 60 seconds; the results are shown in Fig. 6(a). As expected, higher temperatures lead to higher hydrogen production rates. For an applied potential of $1.8 \mathrm{~V}$, the drop in rate for higher temperatures $\left(50\right.$ and $60{ }^{\circ} \mathrm{C}$ ) after $\sim 20 \mathrm{~s}$ is due to the accumulation of gases on the electrode 
surface, and consequently mass transport limitations begin to dominate the effect of higher temperatures leading to faster reaction kinetics. For an applied potential of $2.0 \mathrm{~V}$, the rate increases to a peak value after $\sim 5 \mathrm{~s}$ for all the operating temperatures, and then rapidly decreases because of mass transport limitations. This effect is more pronounced in the case of an applied potential of $2.0 \mathrm{~V}$ due to the faster reaction kinetics. The highest value of the current flux within $60 \mathrm{~s}$ for an applied potential of $1.8 \mathrm{~V}$ is similar to the values from the polarization curve data reported earlier in this paper (Fig. 3(a)). In the case of an applied potential of $2.0 \mathrm{~V}$, however, these values do not compare favorably, as the mass transport limitations are more dominant due to the higher production rate of the gases.

\subsection{Effect of residence time on the hydrogen production rate}

To estimate the hydrogen production rate for each residence time, we calculated the area under the curves in Fig. 6(a), and plot this rate for different applied potentials and operating temperatures (Fig. 6(b)). For an applied potential of $1.8 \mathrm{~V}$, a $60 \mathrm{~s}$ residence time is necessary, which is evident from the increasing rate of hydrogen production with increasing residence time. For an operating temperature of $60{ }^{\circ} \mathrm{C}$, however, a 30 s residence time is sufficient, as the highest $\mathrm{H}_{2}$ production is observed for this residence time. For an applied potential of $2.0 \mathrm{~V}$, the hydrogen production rate reaches a maximum for a residence time of $15 \mathrm{~s}$ for all temperatures, and higher residence times result only in a lower effective rate of hydrogen production. Hence it can be concluded that shorter residence times or pulse durations are preferred for higher applied potentials, due to need for faster removal of the evolved gases.

Table 1 lists the relative values of hydrogen production rate compared to the production rate at $25^{\circ} \mathrm{C}$, i.e., $\left\{\dot{\mathrm{m}}\left(\mathrm{H}_{2}\right)\right\} /\left\{\dot{\mathrm{m}}\left(\mathrm{H}_{2}\right)\right.$ at $\left.25^{\circ} \mathrm{C}\right\}$, for different temperatures and different residence 
times and for applied potentials of 1.8 and $2.0 \mathrm{~V}$, so using the data reported in Fig. 6. For the 1.8 V case, typically higher temperatures and higher residence time led to a higher relative increase in hydrogen production compared to room temperature operation, the highest increase (factor of 7) being for $60{ }^{\circ} \mathrm{C}$ operating temperature and $30 \mathrm{~s}$ residence time. Note that the increase is lower for the higher applied potential, 2.0 V, (the highest value of factor being 2.5) as the mass transport limitations caused by accumulation of the gases at the electrodes is a more dominant effect than the influence of temperature on reaction kinetics.

\section{Summary and Conclusion}

Here we describe the design, fabrication, operation and characterization of a microchannel water electrolyzer. The planar design of the electrolyzer enables convenient fabrication and integration with other energy devices, such as a photovoltaic cell. We showed that the balance between mass (bubble and gas formation at the electrode) and ion/charge (electrical resistance across the electrolyzer chamber) determines the optimal chamber thickness (400 $\mu \mathrm{m}$ in our experiments). Higher temperatures led to higher hydrogen production rate because of the faster reaction kinetics, and also delayed the effect of mass transport limitations. Higher flow rates resulted in higher hydrogen production rate due to more efficient removal of the produced gases accumulated at the electrodes. The higher flow rates, however, caused slower heating of the electrolyte. Hence, we described a pulsed or residence time operation to address this issue of balance between mass and heat transfer limitations. Typically the duration between the pulses (residence time) should be lower in the cases of higher rate of hydrogen production, such as in the cases of higher temperatures and higher applied potential. By performing a systematic, parametric study, we demonstrated that the hydrogen production rate 
can be increased by 7 -fold by tuning the operating temperature, flow rates, residence time and applied potential. In this study, we did not discuss the procedure for collecting hydrogen; an area of future research could be tuning the gas collection procedure and the pulsed operation to maximize hydrogen production and collection.

Although the amount of hydrogen produced by the described microchannel water electrolyzer may not be sufficiently high to function as a stand-alone energy source, the electrolyzer can be integrated with other energy devices, such as a PV cell. The integration of the electrolyzer with a PV cell potentially represents a significant improvement over current photovoltaic thermal (PVT) systems due to the additional energy output (production of hydrogen). In this study, we used a flexible heater to mimic the waste heat produced by a PV cell. A more thorough validation of the integrated approach will require coupling the water electrolyzer with a PV cell, which is a topic of future research. Although we discuss the electrolyzer within the context of an integrated PVTE system, several results of the study, including the planar design and the pulsed operation, are applicable to other energy and electrochemical conversion devices.

\section{Acknowledgements}

We acknowledge support for this work (MEO and RGN) as part of the 'Light-Material Interactions in Energy Conversion' Energy Frontier Research Center funded by the U.S. Department of Energy, Office of Basic Energy Sciences under Award Number DE-SC0001293. We also acknowledge financial support from the National Science Foundation under awards CMMI 03-28162 and CMMI 07-49028 to Nano-CEMMS, a Nano Science \& Engineering Center 
(NSEC) on Nanomanufacturing, for PJAK and AVD. We acknowledge Evan M. Erickson for helpful discussions.

\section{References}

[1] J. Nowotny, T.N. Veziroglu, International Journal of Hydrogen Energy, 36 (2011) 1321813224.

[2] N. Armaroli, V. Balzani, Chemsuschem, 4 (2011) 21-36.

[3] M.A. Modestino, S. Haussener, Annu Rev Chem Biomol, 6 (2015) 13-34.

[4] J.G.G. Clua, R.J. Mantz, H. De Battista, International Journal of Hydrogen Energy, 33 (2008) 3455-3459.

[5] T.L. Gibson, N.A. Kelly, International Journal of Hydrogen Energy, 33 (2008) 5931-5940.

[6] A. Djafour, M. Matoug, H. Bouras, B. Bouchekima, M.S. Aida, B. Azoui, International Journal of Hydrogen Energy, 36 (2011) 4117-4124.

[7] T. Maeda, H. Ito, Y. Hasegawa, Z.M. Zhou, M. Ishida, International Journal of Hydrogen Energy, 37 (2012) 4819-4828.

[8] A. Garrigos, J.L. Lizan, J.M. Blanes, R. Gutierrez, International Journal of Hydrogen Energy, 39 (2014) 20907-20919.

[9] K. Zeng, D. Zhang, Progress in Energy and Combustion Science, 36 (2010) 307-326.

[10] A. Ursua, P. Sanchis, International Journal of Hydrogen Energy, 37 (2012) 18598-18614.

[11] P.M. Dieguez, A. Ursua, P. Sanchis, C. Sopena, E. Guelbenzu, L.M. Gandia, International Journal of Hydrogen Energy, 33 (2008) 7338-7354.

[12] S. Licht, L. Halperin, M. Kalina, M. Zidman, N. Halperin, Chem Commun, (2003) 30063007.

[13] S. Licht, J Phys Chem B, 107 (2003) 4253-4260.

[14] S. Licht, O. Chitayat, H. Bergmann, A. Dick, H. Ayub, S. Ghosh, International Journal of Hydrogen Energy, 35 (2010) 10867-10882.

[15] A. Royne, C.J. Dey, D.R. Mills, Sol Energ Mat Sol C, 86 (2005) 451-483.

[16] E. Skoplaki, J.A. Palyvos, Solar Energy, 83 (2009) 614-624.

[17] P.G. Charalambous, G.G. Maidment, S.A. Kalogirou, K. Yiakoumetti, Applied Thermal Engineering, 27 (2007) 275-286.

[18] S.A. Kalogirou, Progress in Energy and Combustion Science, 30 (2004) 231-295.

[19] A. Shah, P. Torres, R. Tscharner, N. Wyrsch, H. Keppner, Science, 285 (1999) 692-698.

[20] M.E. Oruc, A.V. Desai, P.J.A. Kenis, R.G. Nuzzo, submitted.

[21] S.M. Mitrovski, L.C.C. Elliott, R.G. Nuzzo, Langmuir, 20 (2004) 6974-6976.

[22] L. Zhu, D. Kim, H. Kim, R.I. Masel, M.A. Shannon, J Power Sources, 185 (2008) 13341339.

[23] A.V. Pattekar, M.V. Kothare, J Microelectromech S, 13 (2004) 7-18.

[24] T. Kim, S. Kwon, J Micromech Microeng, 16 (2006) 1760-1768.

[25] J. Xuan, D.Y.C. Leung, M.K.H. Leung, M. Ni, H.Z. Wang, International Journal of Hydrogen Energy, 37 (2012) 2614-2622.

[26] P. Reuse, A. Renken, K. Haas-Santo, O. Gorke, K. Schubert, Chem Eng J, 101 (2004) 133141. 
[27] E. Kjeang, N. Djilali, D. Sinton, J Power Sources, 186 (2009) 353-369.

[28] T.A. Davis, S.L. Athey, M.L. Vandevender, C.L. Crihfield, C.C.E. Kolanko, S. Shao, M.C.G. Ellington, J.K. Dicks, J.S. Carver, L.A. Holland, Journal of Chemical Education, (2014). [29] M.A. Modestino, C.A. Diaz-Botia, S. Haussener, R. Gomez-Sjoberg, J.W. Ager, R.A. Segalman, Physical Chemistry Chemical Physics, 15 (2013) 7050-7054.

[30] H. Zhou, G. Li, S. Yao, Lab on a Chip, 14 (2014) 1917-1922.

[31] C. Casati, P. Longhi, L. Zanderighi, F. Bianchi, J Power Sources, 180 (2008) 103-113.

[32] S.A. Grigoriev, A.A. Kalinnikov, P. Millet, V.I. Porembsky, V.N. Fateev, Journal of Applied Electrochemistry, 40 (2010) 921-932.

[33] T. Ito, K. Maruyama, K. Sobue, S. Ohya, O. Niwa, K. Suzuki, Electroanalysis, 16 (2004) 2035-2041.

[34] S.M. Mitrovski, R.G. Nuzzo, Lab on a Chip, 6 (2006) 353-361.

[35] A.M. Feltham, M. Spiro, Chemical Reviews, 71 (1971) 177-193.

[36] B. Ilic, D. Czaplewski, P. Neuzil, T. Stanczyk, J. Blough, G.J. Maclay, Journal of Materials Science, 35 (2000) 3447-3457.

[37] S. Marini, P. Salvi, P. Nelli, R. Pesenti, M. Villa, M. Berrettoni, G. Zangari, Y. Kiros, Electrochimica Acta, 82 (2012) 384-391.

[38] E. Kjeang, B.T. Proctor, A.G. Brolo, D.A. Harrington, N. Djilali, D. Sinton, Electrochimica Acta, 52 (2007) 4942-4946.

[39] K. Moth-Poulsen, D. Coso, K. Borjesson, N. Vinokurov, S.K. Meier, A. Majumdar, K.P.C. Vollhardt, R.A. Segalman, Energy \& Environmental Science, 5 (2012) 8534-8537.

[40] R.S. Jayashree, L. Gancs, E.R. Choban, A. Primak, D. Natarajan, L.J. Markoski, P.J.A. Kenis, Journal of the American Chemical Society, 127 (2005) 16758-16759. 


\section{Table}

Table 1. The relative total hydrogen production rate with respect to the rate at $25{ }^{\circ} \mathrm{C}$ for different temperatures and different residence time and at the applied potential of 1.8 and $2.0 \mathrm{~V}$.

\begin{tabular}{cccc}
\hline $\begin{array}{c}\text { Temperature } \\
\left({ }^{\circ} \mathbf{C}\right)\end{array}$ & $\begin{array}{c}\text { residence } \\
\text { time } \\
\mathbf{( s )}\end{array}$ & $\begin{array}{c}\text { The ratio } \\
\text { @1.8 V }\end{array}$ & $\begin{array}{c}\text { The ratio } \\
\text { @2.0 V }\end{array}$ \\
\hline $\mathrm{RT}$ & $15-60$ & 1.0 & 1.0 \\
\hline 40 & 15 & 2.8 & 1.8 \\
\hline & 30 & 3.1 & 1.4 \\
\hline & 45 & 3.2 & 1.1 \\
\hline 50 & 60 & 3.3 & 1.1 \\
\hline & 15 & 4.2 & 2.3 \\
\hline & 30 & 4.7 & 1.9 \\
\hline & 45 & 4.9 & 1.5 \\
\hline 60 & 60 & 5.0 & 1.3 \\
\hline & 15 & 6.4 & 2.5 \\
\hline & 30 & 7.0 & 2.0 \\
\hline & 45 & 6.8 & 1.8 \\
\hline & 60 & 5.6 & 1.7 \\
\hline
\end{tabular}




\section{Captions to Figures and Table}

Fig. 1. (a) Schematic illustration of the design and operation of a water electrolyzer integrated with a photovoltaic module. (b) Image of a microchannel water electrolyzer comprising poly(dimethlysiloxane) or PDMS microchannels bonded to a glass substrate with patterned platinum electrodes.

Fig. 2. Fabrication flow of the electrolyzer comprising (I) creation of electrodes and (II) PDMS micromolding.

Fig. 3. (a) Polarization curves for the platinum electrodes ( $\mathrm{Ag} / \mathrm{AgCl}$ reference) for different temperatures $\left(25,50,60,70,80{ }^{\circ} \mathrm{C}\right)$ of the electrolyzer when using $0.5 \mathrm{M} \mathrm{H}_{2} \mathrm{SO}_{4}$ as the electrolyte. Prior to all the experiments, the electrodes were pre-treated by electrolysis in $1 \mathrm{M}$ $\mathrm{H}_{2} \mathrm{SO}_{4}$ at $60{ }^{\circ} \mathrm{C}$ at an applied voltage of $1.8 \mathrm{~V}$ for 2 hours. The dotted lines indicate the values of electrolysis efficiency $(\eta)$ for 1.8 and $2.0 \mathrm{~V}$. The standard deviation in the data is $\sim 0.03$ for all currents and temperatures. (b) Current density during pre-treatment of the platinum electrodes as a function of electrolysis time at an applied voltage of $1.8 \mathrm{~V}$ in $1 \mathrm{M} \mathrm{H}_{2} \mathrm{SO}_{4}$ at $60{ }^{\circ} \mathrm{C}$. The insets show SEM micrographs (at lower and higher magnification) of the electrode before and after 2 hours of electrolysis pre-treatment. The scale bars for the lower and higher magnification micrographs are $10 \mu \mathrm{m}$ and $1 \mu \mathrm{m}$, respectively.

Fig. 4. Effect of flow rate, temperature and chamber thickness on the current density of hydrogen production. The applied potential was $1.8 \mathrm{~V}$ and the electrolyte was $1 \mathrm{M} \mathrm{H}_{2} \mathrm{SO}_{4}$. The Electrodes were pre-treated with $1 \mathrm{M} \mathrm{H}_{2} \mathrm{SO}_{4}$ at $60{ }^{\circ} \mathrm{C}$ under an applied voltage of $1.8 \mathrm{~V}$ for 2 hours. The current density is plotted as a function of time for two different temperatures $\left(25,60{ }^{\circ} \mathrm{C}\right)$ and (a) different electrolyzer chamber thicknesses $(200,400 \mu \mathrm{m})$ for a fixed flow rate of $0.65 \mathrm{~mL}$ $\mathrm{min}^{-1}$, and (b) different electrolyte flow rates $\left(0.5,0.65,1,5 \mathrm{~mL} \mathrm{~min}^{-1}\right)$ for a fixed chamber thickness of $400 \mu \mathrm{m}$. The 'humps between 5 and 10 seconds for the data recorded at the higher temperatures are due to gas bubbles on the electrodes.

Fig. 5. Effect of pulsed operation of residence time approach of the electrolyte on the current density of hydrogen production. Current density is plotted as a function of time for two different temperatures $\left(25,50{ }^{\circ} \mathrm{C}\right) .0 .16 \mathrm{~mL}$ of the electrolyte, $1 \mathrm{M} \mathrm{H}_{2} \mathrm{SO}_{4}$, was replaced after every 60 seconds by pumping at $10 \mathrm{~mL} \mathrm{~min}^{-1}$. The chamber thickness was $400 \mu \mathrm{m}$. Zone I and II indicate the two different behaviors during flushing and post-flushing.

Fig. 6. (a) Current flux of hydrogen production as a function of time the electrolyte resides in the chamber. (b) Hydrogen production rate as a function of residence time for different temperatures $\left(25,40,50,60^{\circ} \mathrm{C}\right)$ and applied potentials $(1.8,2.0 \mathrm{~V})$. The electrolyte was $1 \mathrm{M} \mathrm{H}_{2} \mathrm{SO}_{4}$. 
Table 1. The relative total hydrogen production rate with respect to the rate at $25{ }^{\circ} \mathrm{C}$ for different temperatures and different residence time and at the applied potential of 1.8 and $2.0 \mathrm{~V}$. 


\section{Figures}

\section{Figure 1}

(a)

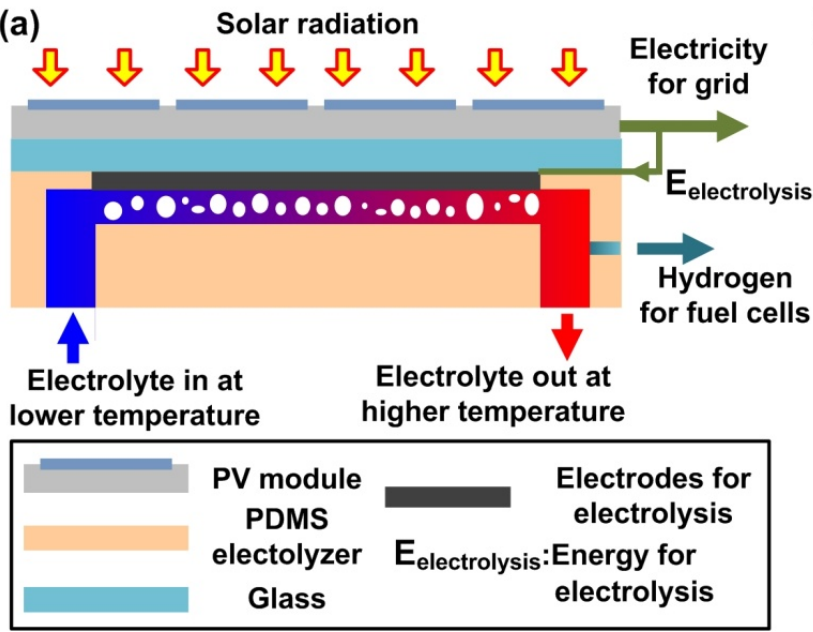

(b)

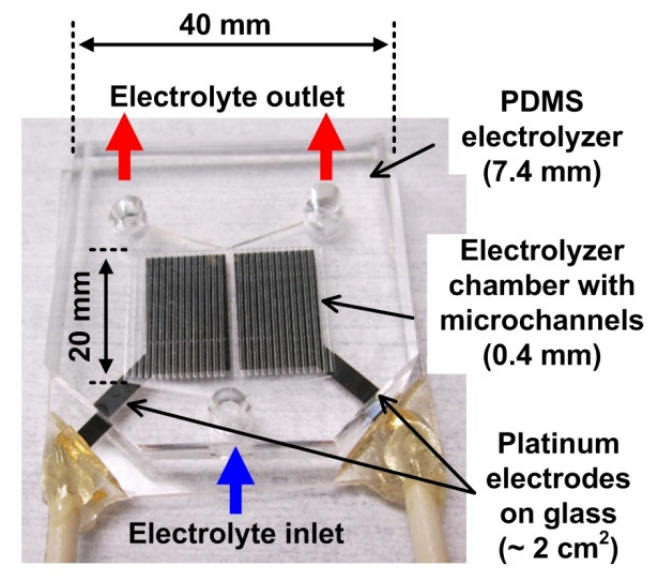

Fig. 1. (a) Schematic illustration of the design and operation of a water electrolyzer integrated with a photovoltaic module. (b) Image of a microchannel water electrolyzer comprising poly(dimethlysiloxane) or PDMS microchannels bonded to a glass substrate with patterned platinum electrodes. 


\section{Figure 2}

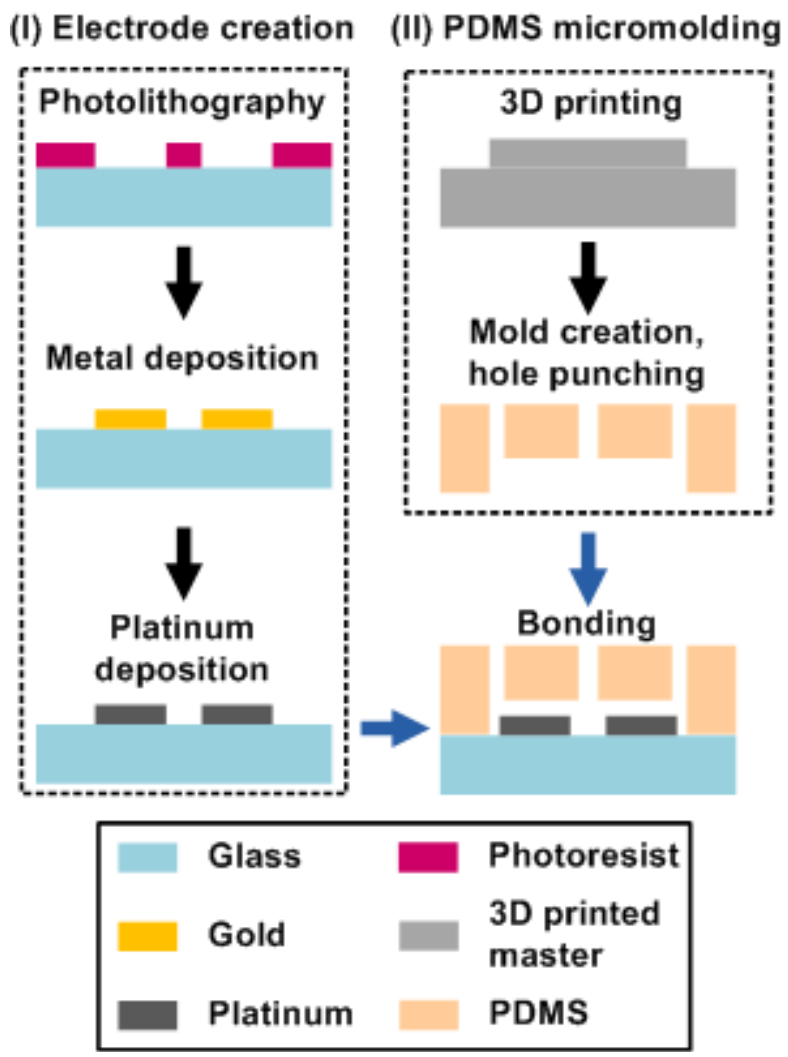

Fig. 2. Fabrication flow of the electrolyzer comprising (I) creation of electrodes and (II) PDMS micromolding. 


\section{Figure 3}
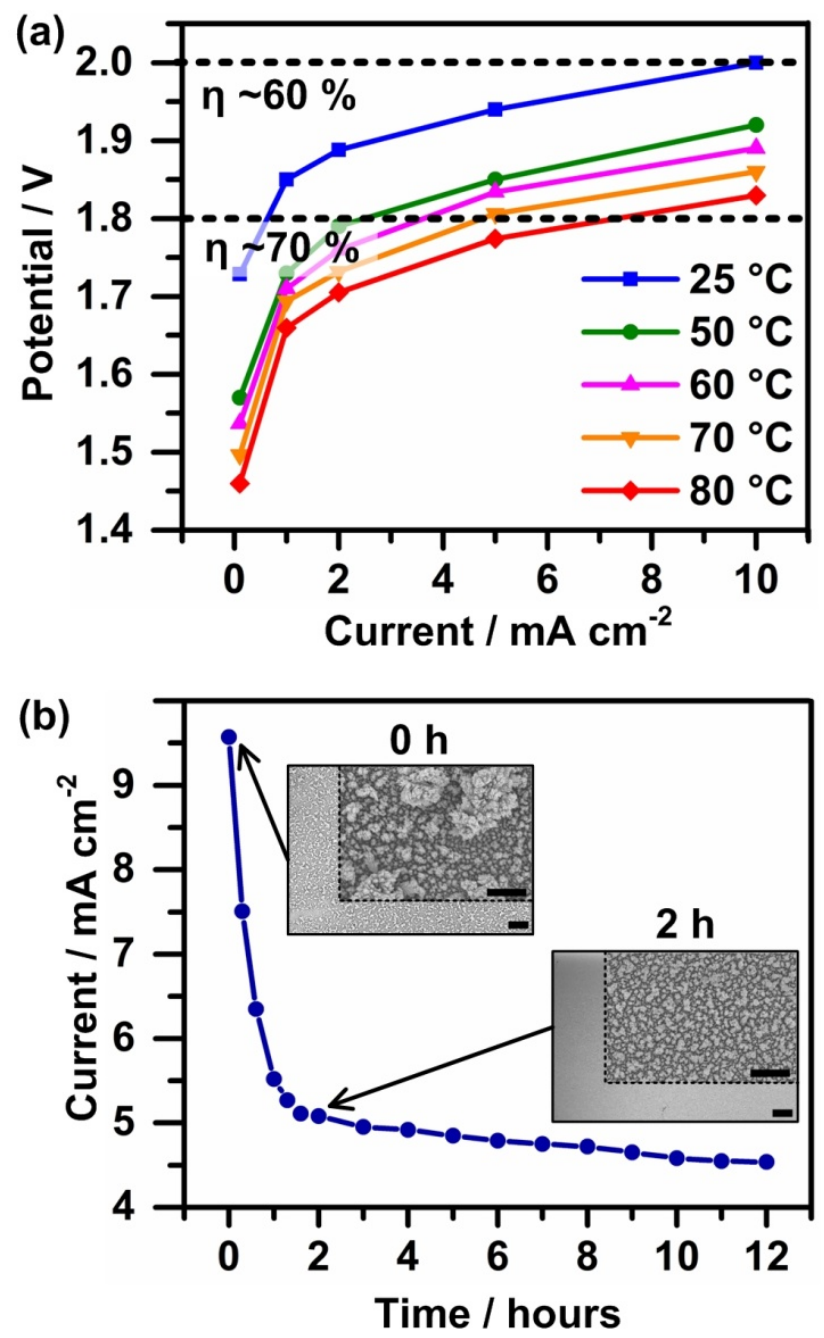

Fig. 3. (a) Polarization curves for the platinum electrodes $(\mathrm{Ag} / \mathrm{AgCl}$ reference) for different temperatures $\left(25,50,60,70,80{ }^{\circ} \mathrm{C}\right)$ of the electrolyzer when using $0.5 \mathrm{M} \mathrm{H}_{2} \mathrm{SO}_{4}$ as the electrolyte. Prior to all the experiments, the electrodes were pre-treated by electrolysis in $1 \mathrm{M}$ $\mathrm{H}_{2} \mathrm{SO}_{4}$ at $60{ }^{\circ} \mathrm{C}$ at an applied voltage of $1.8 \mathrm{~V}$ for 2 hours. The dotted lines indicate the values of electrolysis efficiency $(\eta)$ for 1.8 and $2.0 \mathrm{~V}$. The standard deviation in the data is $\sim 0.03$ for all currents and temperatures. (b) Current density during pre-treatment of the platinum electrodes as a function of electrolysis time at an applied voltage of $1.8 \mathrm{~V}$ in $1 \mathrm{M} \mathrm{H}_{2} \mathrm{SO}_{4}$ at $60{ }^{\circ} \mathrm{C}$. The insets show SEM micrographs (at lower and higher magnification) of the electrode before and after 2 hours of electrolysis pre-treatment. The scale bars for the lower and higher magnification micrographs are $10 \mu \mathrm{m}$ and $1 \mu \mathrm{m}$, respectively. 


\section{Figure 4}
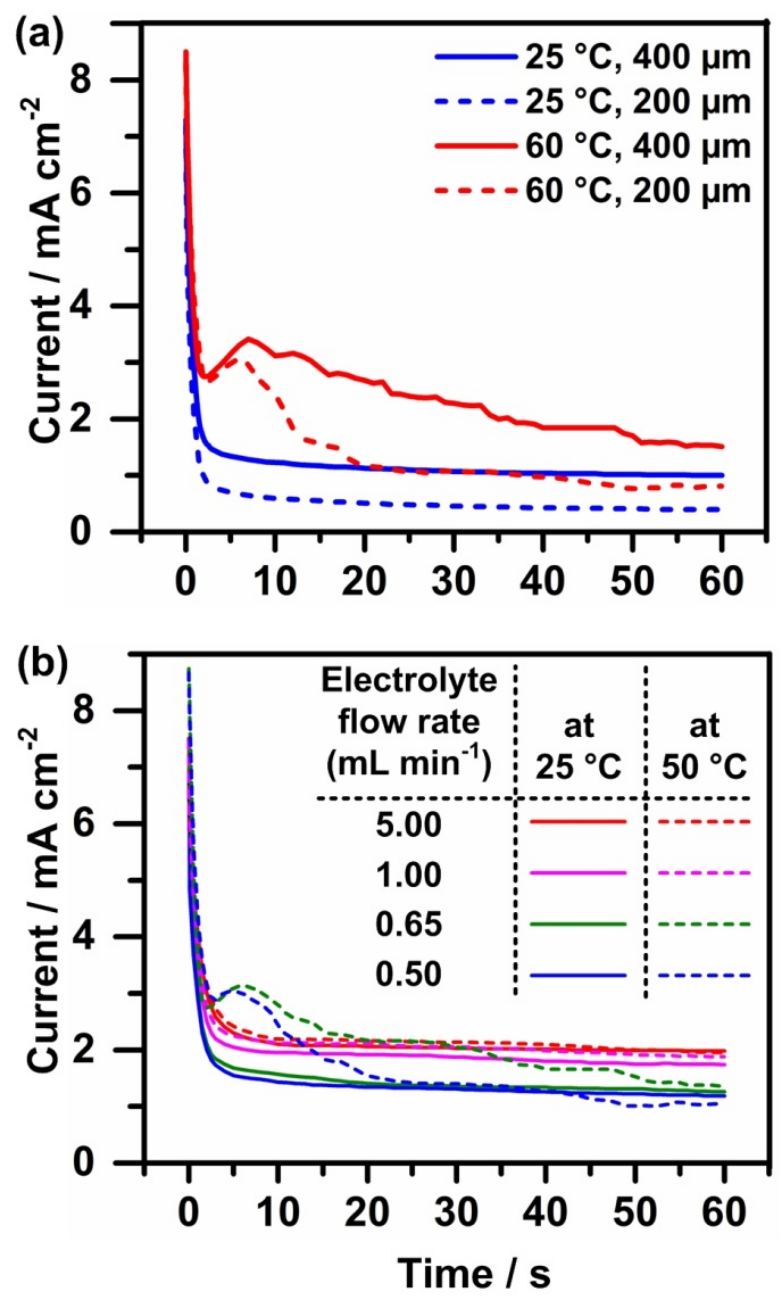

Fig. 4. Effect of flow rate, temperature and chamber thickness on the current density of hydrogen production. The applied potential was $1.8 \mathrm{~V}$ and the electrolyte was $1 \mathrm{M} \mathrm{H}_{2} \mathrm{SO}_{4}$. The Electrodes were pre-treated with $1 \mathrm{M} \mathrm{H}_{2} \mathrm{SO}_{4}$ at $60{ }^{\circ} \mathrm{C}$ under an applied voltage of $1.8 \mathrm{~V}$ for 2 hours. The current density is plotted as a function of time for two different temperatures $\left(25,60^{\circ} \mathrm{C}\right)$ and (a) different electrolyzer chamber thicknesses $(200,400 \mu \mathrm{m})$ for a fixed flow rate of $0.65 \mathrm{~mL}$ $\mathrm{min}^{-1}$, and (b) different electrolyte flow rates $\left(0.5,0.65,1,5 \mathrm{~mL} \mathrm{~min}^{-1}\right)$ for a fixed chamber thickness of $400 \mu \mathrm{m}$. The 'humps between 5 and 10 seconds for the data recorded at the higher temperatures are due to gas bubbles on the electrodes. 


\section{Figure 5}

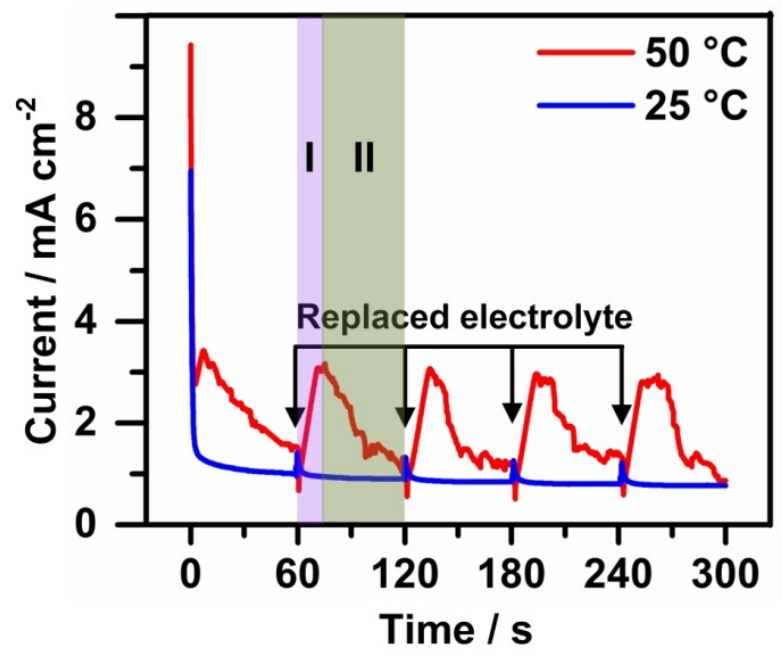

Fig. 5. Effect of pulsed operation of residence time approach of the electrolyte on the current density of hydrogen production. Current density is plotted as a function of time for two different temperatures $\left(25,50{ }^{\circ} \mathrm{C}\right) .0 .16 \mathrm{~mL}$ of the electrolyte, $1 \mathrm{M} \mathrm{H}_{2} \mathrm{SO}_{4}$, was replaced after every 60 seconds by pumping at $10 \mathrm{~mL} \mathrm{~min}^{-1}$. The chamber thickness was $400 \mu \mathrm{m}$. Zone I and II indicate the two different behaviors during flushing and post-flushing. 


\section{Figure 6}
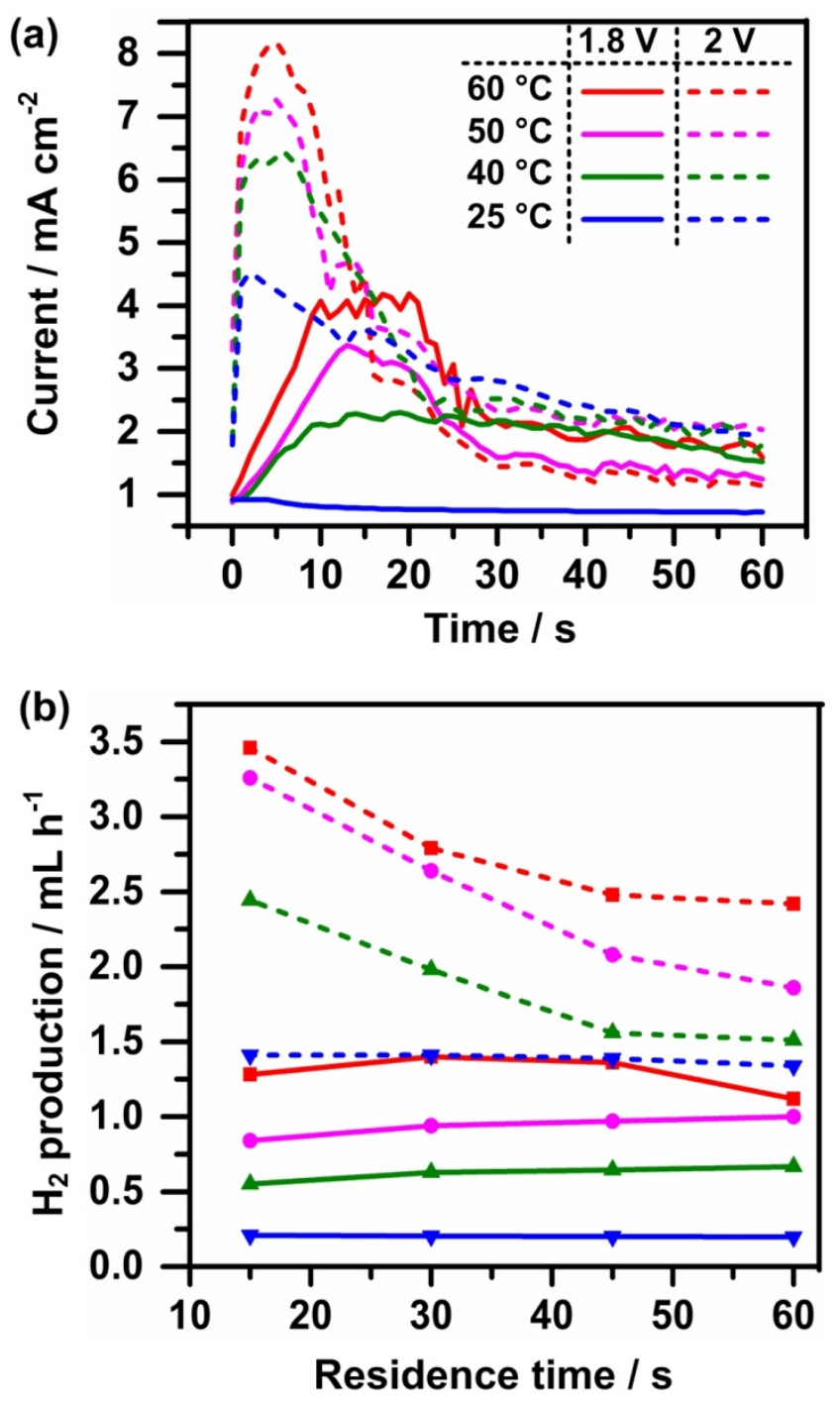

Fig. 6. (a) Current flux of hydrogen production as a function of time the electrolyte resides in the chamber. (b) Hydrogen production rate as a function of residence time for different temperatures $\left(25,40,50,60^{\circ} \mathrm{C}\right)$ and applied potentials $(1.8,2.0 \mathrm{~V})$. The electrolyte was $1 \mathrm{M} \mathrm{H}_{2} \mathrm{SO}_{4}$. 

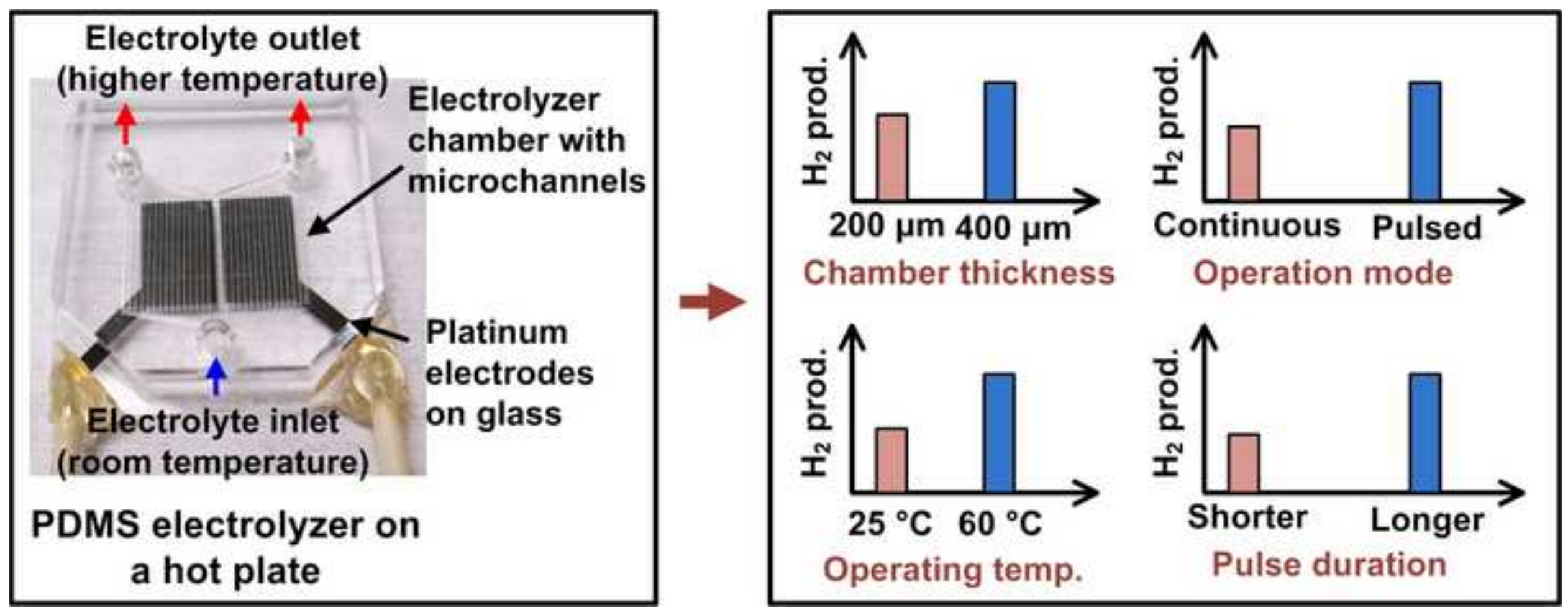